\title{
A Review of Studies of the Role of Native Language
}

\author{
Weihua $\mathrm{Yu}$ \\ Qingdao University of Science and Technology, Qingdao, China \\ Email: yuweihua961126@163.com
}

\begin{abstract}
The role of the native language is a complex one, which influences the second language acquisition to some degree. Famous linguists and psychologists from different schools have got different opinions .The paper reviews and compares their ideas, analyzes the bodily manifestation of transfer as well as various factors influencing transfer.
\end{abstract}

Index Terms - behaviorist, rationalist, transfer

\section{BRIEF HISTORY OF EVOLUTION}

One of the most striking features that distinguish adult L2 learning from child L1 learning is the fact that prior to L2 learning, L2 learners have already had a fully developed native language system in their mind and don't start the L2 learning task completely new. To what extent L1 knowledge facilitates L2 learning has been a perennial issue in the SLA field. In the 1950s when behaviorism was in its prime, the L1 was considered as the single most important factor influencing L2 learning. Contrastive Analysis (CA) was the predominant tool used to locate surface L1-- L2 similarities and differences. But around 1960, Chomsky severely attacked behaviorist's view of language learning. According to his Creative Construction Hypothesis, L2 learning is guide by universal innate principles and treated as identical to L1 learning. A group of L2 researchers such as Dulay and Burt followed him and made a series of studies. Based on the results of their studies, they claimed that like L1 learning, L2 learners followed a natural order of acquiring L2 structures regardless of L1 influence, and L1 influence was minimized in the 1970s.

In spite of the decline of L1 influence in the 1970s, there has been a renewed interest in L1 transfer in the past 20 years or so. This is because L1 transfer is an omnipresent phenomenon throughout L2 learning, which researchers can't afford to ignore in their endeavor to reveal the cognitive mechanisms underlying L2 learning. According to Gass (1996), It has become clear that an explanatory account of L2 acquisition can't be given on the basis of the target language alone. As empirical research develops, the role of L1 in L2 acquisition is increasingly stressed, about which Linguists and psychologists from different schools such as Skinner, Odlin, Dulay etc have made lots of research and formed their own ideas.

\section{KEY IDEAS FROM DIFFERENT SCHOOLS}

\section{A. Behaviorists'Opinions}

According to behaviorist learning theory, old habits get in the way of learning new habits, and SLA is strongly influenced by the learners'L1. There is a popular belief that the role of L1 in SLA is a negative one, that is, L1 gets in the way or interferes with the learning of L2.Some researchers like Bright and Mcgregor (1970) believed that where SLA is concerned, the grammatical apparatus programmed into the mind as the first language interferes with the smooth acquisition of the second. The notion of "interference" was the result of what was called "proactive inhibition". This is concerned with the way in which previous learning prevents or inhibits the learning of new habits. Where the first and second language share a meaning but express it in different ways, an error is likely to arise in L2 because the learner will transfer the realization device from his first language into the second. Therefore, the process of SLA is considered as that of overcoming the effect of L1, of slowly replacing the features of L1 that intrude into L2 with those of the target language, just as Marton (1981) has told us "taking a psychological point of view, we can say that there is never peaceful co-existence between two language systems in the learner, but rather constant warfare, and that warfare is not limited to the moment of cognition, but continues during the period of storing newly learnt ideas in memory" (P.150). That is to say, there is a process of automatic, uncontrolled and subconscious use of past learned behavior in the attempt to produce new responses, and this is called "transfer". In order to learn new language, the learner has to overcome the proactive inhibition, in this case, L1 transfer is considered negative. Others also believes that when L1 and L2 habits are the same, no errors will occur, and the similarities between the first and second language may facilitate rapid and easy learning, in this case, the role of L1 in SLA is positive.

On the basis of Contrastive Analysis, they deal with the conditions under which interference takes place. In their minds, it is not possible to predict or explain the presence or absence of transfer errors solely in terms of linguistic differences between L1 and L2, and another two non-linguistic variables can help to determine whether and when 
interference occurs. One possible variable is the setting in which SLA takes place, and the other may be the learner's stage of development.

\section{B. Rationalists' Opinions}

In 1959, another linguists Chomsky reviewed Skinners' Verbal Behavior, and started his attack on behaviorists' accounts of language learning. He believes that language is somewhat innate, and that children are born with what he calls a Language Acquisition Device (LAD), which is a unique kind of knowledge that fits them for language learning. According to his "Innateness Hypothesis", he argued that language acquisition was developed in nature, driven as much from the inside as from the outside. He dismissed terms like "stimulus, imitation and reinforcement "etc., therefore, language learning could not be explained only in terms of habit-formation, in this case, the question arose as to what exactly interference consisted of. This belief also gained support from other linguists. Felix (1980) proposed that “...our data on L2 acquisition of syntactic structures in a natural environment suggest that interference does not constitute a major strategy in this area...it seems necessary to me to abandon the notion of interference as a natural and inevitable phenomenon in L2 acquisition' (P. 107). On their studies, Dulay and Burt (1973) argued that children do not organize the L2 on the basis of transfer or comparison with their L1, but rely on their ability to construct the L2 as an independent system, in much the same way as in L1 acquisition. They suggested that interference may be a major factor only in phonology.

\section{Reappraisal of the Role of $L 1$}

As time goes on, in recent years there has been a successful reappraisal of the role of the L1 in SLA. Wode (1976) argued that the notion of interference had to be developmentalized if it was to provided any fruitful insights, and he concluded that "certain conditions have to be met for what is commonly called interference to take place at all" (P.27). Empirical evidence showed that interference was more likely to take place when there was some similarity between the first and second language items than when there was total difference, and most important, it was recognized that error was a multi-factor phenomenon and that interference, as one of the factors, interacted in complex ways with other factors. Corder (1978) outlines one way in which "interference" can be recast as a learner "strategy". He suggests that the learner's L1 may facilitate the developmental process of learning a L2, by helping him to progress more rapidly along the universal route when the L1 is similar to the L2. Interference errors result not from negative transfer but from "borrowing". That is, when learners experience difficulty in communicating an idea because they lack the necessary target language resources, they will resort to their L1 to make up the insufficiency. In effect, Corder's proposal reframes the concept of "interference" as "intercession".

It is now widely accepted that the influence of the learners' native language can not be adequately accounted for in terms of habit formation, nor is transfer simply a matter of interference or of falling back on the native language, as other previously acquired second languages can also have an effect. This suggests that the term "transfer" itself is inadequate. Sharwood-Smith and Kellerman (1986) have argued that a superordinate term is needed and they coined the term "crosslinguistic influence". In their opinions, crosslinguistic influence is theory-neutral, allowing one to subsume under one heading phenomena such as 'transfer', 'interference', 'avoidance', 'borrowing' and L2-related aspects of language loss. Another famous linguist Odlin(1989)offers another definition of transfer. He comments that transfer is the influence resulting from the similarities and differences between the target language and any other language that has been previously acquired.

\section{BODILY MANIFESTATION}

Ellis (1994) argues that no theory of L2 acquisition is complete without an account of L1 transfer. Since the L1 system is highly automatized through repeated activation, L1 transfer occurs inevitably, and both the similarity and difference between L1 and L2 may lead to L1 transfer, which can be shown in the following forms:

\section{A. Negative Transfer}

The 1960s saw a number of studies of linguistic errors produced by L1 learners. According to Richards, errors occurred primarily as a result of interference when learners transferred native language habits into L2. Interference was believed to take place whenever the habits of the native languages differed from those of L2. Lott (1983) distinguished three categories of transfer errors: (a) overextension of analogy occurs when the learner misuses an item because it shares features with an item in L1. (b) transfer of structure arises when the learner utilizes some L1 feature rather than that of the target language. (c) interlingual errors arise when a particular distinction does not exist in L1. Studies show that learners at an elementary level produced more transfer errors than learners at an intermediate or advanced level. In addition, according to Grauberg (1971), they are more common in the phonological and lexical levels of language than in the grammatical level.

\section{B. Positive Transfer}

In some cases, when both the L1 and the L2 have the same form, pattern or rule, the transfer facilitates learning, and this is positive transfer, which results in correct performance, because the new behavior is the same as the old. For example, when Chinese speakers learn English, they learn the word of 'He comes from Beijing' very easily. It is just 
because Chinese word order is similar to English word order. Ellis (1994) points out that the facilitative effect of L1 is evident in the early stages of acquisition before the learner is ready to construct a developmental rule. Because facilitation is not as evident as interference, Odlin (1989) argues that the facilitative effect of L1 depends on the reduced number of errors and the rate of learning.

\section{Avoidance}

Learners also avoid using linguistic structures which they find difficult because of differences between their L1 and L2. In Kellerman's (1992) opinion, avoidance is a complex phenomenon, which can fall into three types: (a) avoidance occurs when learners know or anticipate that there is a problem and have at least some sketchy idea of what the target form is like. This is the minimum condition for avoidance. (b) avoidance arises when learners know what the target is but find it too difficult to use in the particular circumstances. (c) avoidance is evident when learners know what to say and how to say it but are unwilling to actually say it because it will result in them flouting their own norms of behavior. Certainly much more is involved than learners' L1 in all these three cases. Both the extent of learners' knowledge of L2 and the attitudes learners hold toward the native and the target language cultures act as factors that interact with L1 knowledge to determine avoidance behavior.

\section{Over-use}

The over-use as a result of transfer can be shown in two ways: first, the over-indulgence of certain grammatical forms in L2 acquisition can occur as a result of intralingual processes such as overgeneralization. For example, L2 learners have often been observed to overgeneralize the regular past tense inflection to irregular verbs in L2. Second, over-use is also evident at the discourse level. According to Olshtain (1983), the native speakers of English who learned L2 Hebrew used more direct expressions of apology than native speakers of Hebrew and they tended to transfer this into L2 Hebrew.

\section{FACTORS INFLUENCING TRANSFER}

\section{A. Language Factors}

Studies have shown that transfer may occur in different levels of language such as phonology, lexis, grammar and discourse etc, among which transfer at the level of phonology is the most obvious. The existence of "foreign accent" in L2 learning may clarify it. "Foreign accent" mainly results from the difference in phonemic inventory and pronunciation between L1 and L2. For example, the pronouncing pattern of Chinese is vowel or consonant-vowel, that is, V/CV pattern, whereas the pronouncing pattern of English word is vowel or vowel-consonant or consonant-vowel-consonant, that is, V/VC/CVC pattern. Consequently, vowel may often be added when Chinese students pronounce such words as /desks/, forming the pronunciation /desə kə s /. Likewise, foreign students can often read "nihào" instead of the correct one "nihăo".

In grammar, transfer may also occur in word order, clause and negative structures. The position of adverbs is different in English and Chinese when they are used to modify verbs. In Chinese, adverbs are often put in front of verbs, whereas in English, adverbs are often put at the end of a sentence. Therefore, Chinese students may transfer Chinese word order into English, making such sentences as "I very much like beer". Thus it can be seen that the difference between L1 and L2 in different levels of language can result in transfer.

\section{B. Non-language Factors}

The purpose of learning L2 is to use it, so the social context and the relationship between speakers may influence L1 transfer. Odlin (1989) suggested there are two kinds of social context: focused context and unfocused context; the former is formal context where speakers constitute a "focused" community and as a consequence treat L1 forms as intrusive and even stigmatized, trying to maintain the standardness of L2; the latter is informal or natural context where speakers comprise an "unfocused" community, and therefore language mixing is freely permitted, thus encouraging negative transfer to take place. In terms of L1 transfer, the possibility of L1 interference in focused context is smaller than in unfocused context. For example, in English classroom, negative transfer is less common than in natural settings. Even if it occurs, it may be corrected in time.

The distance between L1 and L2 can also affect L1 transfer. Ellis points out that language distance can be viewed as both a linguistic phenomenon and a psycholinguistic phenomenon. The former refers to the degree of actual linguistic difference between two languages, the latter means the degree of difference between two languages in learners' opinion, which Kellerman (1979) called "psychotypology". This term reflects learners' perceptions about language distance. If learners perceive that there is a great difference between L1 and L2, then L1 transfer is unlikely to occur, otherwise it may do.

\section{CONCLUSION}

In sum, the role of the first language is a highly complex one. Although in popular belief SLA is strongly influenced by the learner's L1, there is considerable disagreement among researchers about the extent and nature of the role of the L1.Now it is clearly that the learner's L1 is an important determinant of SLA, but it is not the only determinant, and 
may not be the most important. The L1 is a resource of knowledge which learners will use both consciously and subconsciously to help them sift the L2 data in the input and to perform as best as they can in the L2. Precisely when and how this resource is put to use depends on a whole host of factors to do with the formal and pragmatic features of the native and target languages and the learner's stage development and type of language use.

In our English teaching, we may find that most of students think in Chinese first and then translate when they learn English, so L1 transfer is unavoidable. Lado (1957) points out that the teacher who has made a comparison of the foreign language with the native language of the students will know better what the real problems are and can provide for teaching them. Therefore, study on the role of native language is very important for us to know more about L2 acquisition, which must instruct our teaching and then improve our teaching quality.

\section{REFERENCES}

[1] Bright J and G. McGregor. (1970) .Teaching English as a Second Language: Theory and Techniques for the Secondary stage. London: Longman.

[2] Corder, S. (1978b). 'Language distance and the magnitude of the learning task'. Studies in Second Language Acquisition2/1.

[3] Cheng-xian Tang. (2003). A Review of First Language Transfer Studies in Second Language Acquisition, Journal of PLA University of Foreign Languages.

[4] Dulay, H. and M. Burt. (1973). 'Should we teach children syntax?'. Language Learning23.

[5] Ellis,R. (1994).Understanding Second Language Acquisition, Shanghai Foreign Language Education.

[6] Felix, S. (1980b). 'Interference, interlanguage and related issues' in Felix(ed.)1980a.

[7] Gass, S. (1996). Second Language Acquisition and Linguistic Theory: The Role of Language Transfer. In Ritchie, W.C.and Bhatia, T. Handbook of Second Language Acquisition. San Diego: Academic Press,

[8] Grauberg, W. (1971). 'An error analysis in the German of first-year university students' in Perren and Trim (eds.)1971.

[9] Kellerman, E. \& M. Sharwood Smith eds. (1986). Crosslinguistic Influence in Second Language Acquisition. New York: Pergamon Press

[10] Kellerman, E. (1979). Transfer and non-transfer: where are we now? Studies in Second Language Acquisition.

[11] Lado, R. (1957). Linguistics Across Cultures: Applied Linguistics for Language Teachers. Ann Arbor, Michigan: University of Michigan.

[12] Lott, D. (1983). 'Analysing and counteracting interference errors'. ELT Journal 37/3.

[13] Marton, W. (1981). 'Contrastive analysis in the classroom' in Fisiak (ed) 1981.

[14] Odlin, T.(1989). Language Transfer. Cambridge: Cambridge University Press.

[15] Wode, H. (1976). 'Developmental sequences in naturalistic L2 acquisition'. Working papers in Bilingualism 11.

Weihua Yu was born in Qingdao, China in 1968. She received her M.A. degree in linguistics from Ocean University of China, China in 2006.

She is currently an associate professor in the School of Foreign Languages, Qingdao University of Science and Technology, Qingdao, China. Her research interests include foreign linguistics and applied linguistics as well as second language acquisition. 